\title{
Pengaruh Metode Pembelajaran Type Talking Stick Terhadap Hasil Belajar IPA pada Siswa Kelas 4 Sekolah Dasar
}

\author{
Meirza Nanda Faradita \\ Program Studi Pendidikan Guru SD, Universitas Muhammadiyah Surabaya \\ meirzananda@fkip.um-surabaya.ac.id
}

\begin{abstract}
Abstrak
Banyak siswa yang merasa takut dan malu untuk menjawab pertanyaan yang diberikan oleh pendidik pada mata pelajaran IPA dan siswa juga jarang atau hampir tidak pernah berusaha untuk mengungkapkan pendapat mereka. Hal ini terjadi karena metode pembelajaran yang digunakan biasanya adalah metode ceramah dan terkadang hal tersebut kurang sesuai dengan materi yang diajarkan. Tujuan penelitian untuk mengetahui pengaruh metode pembelajaran cooperative learning type talking stick terhadap hasil belajar IPA pada siswa kelas IV. Rancangan penelitian ini jenis eksperimen dengan type one group pretest - posttest design. populasi adalah seluruh siswa kelas IV sebanyak 30 siswa yang terdiri dari 15 orang siswa laki-laki dan 15 orang siswa perempuan. Penelitian ini dilaksanakan di Sekolah dasar Taman Sidoarjo. Sampel pada penelitian ini diambil dengan teknik sampling jenuh sebanyak 30 responden. data dikumpulkan dengan instrument kuesioner dan dianalisa dengan uji one sampel $t$ test. Hasil uji one sampel T test menunjukkan bahwa nilai $\rho=0,00$ dari hasil pre dan post test berarti nilai $\rho<\alpha$, dengan $\alpha=0,05$ maka hal ini menunjukkan terdapat perbedaan hasil belajar siswa dalam mengerjakan soal IPA sebelum dan setelah dilakukan metode talking stick. Berdasarkan nilai rata-rata kelompok menunjukkan data nilai rata-rata pada saat pre test sebesar 56,8, dan nilai rata-rata kelompok post test sebesar 71. Model pembelajaran cooperative dikembangkan untuk mencapai hasil belajar berupa prestasi akademik, toleransi, menerima keragaman, dan pengembangan keterampilan sosial. Lebih lanjut tujuan pokok pembelajaran kooperatif adalah untuk dapat memaksimalkan belajar siswa agar peningkatan prestasi akademik dan pemahaman tercapai dengan, baik secara individu maupun secara kelompok.
\end{abstract}

Kata Kunci : Talking Stick, Hasil Belajar, IPA

\begin{abstract}
Many students are afraid and embarrassed to answer questions provided by educators on science subjects and students also rarely or hardly ever attempt to express their opinions. This happens because the learning method used is usually a lecture method and sometimes it is less in accordance with the material being taught. The purpose of research to determine the influence of cooperative learning method type talking stick to the results of science learning in grade IV students. The design of this study type experiment with type one group pretest - posttest design. the population is all students of class IV of 30 students consisting of 15 male students and 15 female students. This research was conducted at Taman Sidoarjo elementary school. The sample in this research is taken with saturated sampling technique as many as 30 respondents. data were collected by questionnaire instrument and analyzed by one sample t test. The test result of one sample T test shows that the value of $\rho=0.00$ of the pre and post test mean value $\rho<\alpha$, with $\alpha=0,05$ then this indicates there is difference of result of student learning in doing science problem before and after done method talking stick. Based on the average value of the group shows the average value data at the time of pre test of 56.8, and the average value of the post test group of 71. Cooperative learning model developed to achieve learning outcomes in the form of academic achievement, tolerance, accepting diversity, and the development of social skills. Furthermore, the main objective of cooperative learning is to maximize student learning in order to improve academic achievement and understanding achieved with, either individually or in groups.
\end{abstract}

Keywords: Talking Stick, learning outcomes, Sains. 


\section{PENDAHULUAN}

Pendidikan dilakukan melalui suatu usaha yang dilaksanakan secara terencana dan bertujuan untuk mengubah manusia dari yang tidak tahu menjadi tahu. Pendidikan akan merangsang tumbuhnya kreativitas seseorang agar sanggup menghadapi perkembangan jaman yang semakin maju. Indonesia sebagai salah satu Negara yang berkembang masih perlu melakukan peningkatan pembangunan di segala sektor.

Upaya yang dapat dilakukan untuk memenuhi tantangan jaman adalah dengan melakukan pembaharuan pendidikan secara terencana, terarah, dan berkesinambungan. Strategi peningkatan mutu pendidikan dalam proses pembelajaran merupakan upaya pembaharuan pendidikan yang dapat dilakukan oleh guru dan sebagai fasilitator dalam kegiatan belajar mengajar.

Hasil observasi yang dilakukan peneliti diperoleh dari hasil nilai UTS siswa kelas IV Sekolah dasar menunjukkan 65\% siswa belum mencapai KKM dan $35 \%$ yang hasil belajarnya telah mencapai KKM dengan target KKM yang ditetapkan yaitu nilai 75. Berdasarkan hasil belajar diatas dapat dilihat bahwasannya proses pembelajaran Ilmu Pengetahuan Sosial masih menekankan pada aspek kognitif dibandingan dengan aspek afektif.

Seharusnya ilmu pengetahuan sosial menerapkan 3 aspek yaitu kognitif, afektif, dan psikomotor. Pola pikir siswa SD pada umumnya masih bersifat konkrit atau nyata, sehingga banyak siswa yang menganggap mata pelajaran IPA termasuk pelajaran yang mudah. Banyak siswa yang merasa takut dan malu untuk menjawab pertanyaan yang diberikan oleh pendidik dan siswa juga jarang atau hampir tidak pernah berusaha untuk mengungkapkan pendapat mereka. Hal ini terjadi karena metode pembelajaran yang digunakan biasanya adalah metode ceramah dan terkadang hal tersebut kurang sesuai dengan materi yang diajarkan serta karena terbatasnya media pembelajaran yang tersedia di sekolah menyebabkan para guru merasa kesulitan untuk menyajikan materi pada saat proses pembelajaran IPA berlangsung. Kesulitan yang dialami oleh pendidik diantaranya siswa masih terlihat kurang aktif, karena proses pembelajaran terpusat 
pada guru, siswa banyak yang tidak terlalu memperhatikan pembelajaran yang diberikan sehingga pemahaman siswa masih banyak yang kurang.

Proses pembelajaran di kelas dapat dikatakan berhasil jika didukung dengan penggunaan strategi pembelajaran yang baik seperti pemilihan metode pembelajaran. Selain itu guru harus pula mengerti dan memahami karakteristik dari pelajaran yang akan diberikan dan karakter peserta didik sehingga proses pembelajaran akan lebih variatif dan inovatif dalam merekonstruksi wawasan pengetahuan serta implementasi sehingga akan meningkatkan hasil belajar siswa. Untuk itu, pengenalan keanekaragaman budaya Indonesia dalam rangka melestarikan budaya perlu ditransformasikan dalam bidang pendidikan, yang salah satunya pada mata pelajaran IPA Sekolah dasar materi keanekaragaman budaya dengan menggunakan metode pembelajaran yang kreatif dan inovatif.

Selain menggunakan model yang lebih variatif dan inovatif guru juga perlu mengembangkan berbagai sumber belajar yang dapat menunjang kegiatan pembelajaran, sehingga kegiatan pembelajaran berlangsung dengan lebih menarik dan dapat mengembangkan keaktifan serta kreatifitas siswa yaitu dengan menggunakan aneka sumber belajar. Dengan menerapkan model pembelajaran kooperatif Talking Stick maka kegiatan pembelajaran dapat berlangsung dengan lebih menarik dan menyenangkan sehingga siswa lebih aktif dan dapat mengembangkan pengetahuan yang dimiliki dengan mencari berbagai sumber belajar sendiri, dengan itu maka dapat mempengaruhi hasil belajar IPA siswa menjadi lebih baik. Model talking stick mendorong peserta didik berani mengemukakan pendapat. Pembelajaran diawali penjelasan guru mengenai materi pokok yang akan dipelajari. Peserta didik diberi kesempatan membaca, mempelajari materi tersebut. Guru memberikan waktu cukup untuk aktivitas ini. Selanjutnya meminta peserta didik menutup bukunya. Guru mengambil tongkat yang telah dipersiapkan. Tongkat diberikan kepada salah satu peserta didik. Peserta didik yang menerima tongkat tersebut diwajibkan menjawab pertanyaan guru demikian seterusnya. 
Terdapat beberapa kelebihan dan kelemahan dalam model pembelajaran type Talking Stick. Kelebihan model Talking Stick yaitu menguji kesiapan siswa, melatih siswa memahami materi dengan cepat, agar siswa lebih giat belajar (belajar dahulu sebelum pelajaran di mulai), sedangkan kelamahan model pembelajaran ini adalah membuat siswa tegang karena takut pertanyaan yang harus dijawab.

Pada proses pembelajaran IPA guru SD perlu menggunakan model pembelajaran yang berpusat pada siswa, kreatif, dan inovatif. Agar siswa menjadi aktif dalam kegiatan pembelajaran dan siswa dapat memperoleh pengalaman belajar yang bermakna dan menyenangkan. Dengan demikian siswa akan memperoleh manfaat dari mata pelajaran IPA dalam kehidupannya sehari- hari. Salah satu model pembelajaran inovatif yang dapat dijadikan alternatif dalam pembelajaran IPA adalah model pembelajaran kooperatif tipe talking stick.

\section{METODE PENELITIAN}

Dalam penelitian ini, peneliti menggunakan pendekatan kuantitatif. Metode yang digunakan adalah metode penelitian eksperimen. Rancangan desain yang digunakan yaitu one group pretest - posttest design. Rancangan desain dalam penelitian ini sebagai berikut :

$$
\mathrm{O}_{1} \mathrm{X} \mathrm{O}_{2}
$$

\section{Keterangan:}

$\mathrm{O}_{1} \quad$ : Nilai Pretest (sebelum diberi Perlakuan)

$\mathrm{O}_{2} \quad$ : Nilai Posttest (setelah diberi perlakuan)

$\mathrm{O}_{2-} \mathrm{O}_{1}$ : pengaruh diberikannya perlakuan

Sumber data pada penelitian ini yaitu informan. Informan dalam penelitian ini adalah siswa dan guru. Tempat penelitian merupakan sebagai tempat dalam melakukan kegiatan penelitian untuk memperoleh data dari 
responden.

Bentuk data penelitian ini adalah data primer dan data sekunder. Data primer adalah data yang diperoleh atau dikumpulkan oleh peneliti secara langsung dari sumber datanya. Teknik yang dapat digunakan peneliti untuk mengumpulkan data primer antara lain observasi, wawancara, diskusi terfokus (focus grup discussion - FGD) dan penyebaran kuesioner. Instumen pengumpulan data yang digunakan pada penelitian ini adalah lembar kerja siswa yang dibuat berdasarkan materi yang telah disampaikan oleh peneliti. Lembar kerja siswa pada penelitian ini berisi implementasi model pembelajaran yang digunakan oleh guru dalam proses KBM berlangsung. Tes hasil belajar yang digunakan dalam penelitian ini adalah soal pretest dan posttest. Hasil belajar dinilai dengan teknik test sesuai dengan soal yang telah disusun.

Sebelum digunakan penelitian, instrument penelitian hendaknya memenuhi dua persyaratan uji instrument yaitu valid dan reliable. Persyaratan tersebut diuji dengan uji sebagai berikut : 1) Uji validitas dalam penelitian ini yaitu dengan mengikuti kaidah product moment (r) yaitu dengan cara mengkorelasi setiap skor item dengan total score item variabel, kemudian hasil korelasi dibandingkan dengan nilai kritis pada taraf siginifikan 0,05. Suatu instrumen dikatakan valid apabila nilai hasil korelasi lebih besar dari nilai kritis pada tabel yang telah ditentukan begitu juga sebaliknya. Dalam uji validitas menggunakan rumus sebagai berikut:

$$
r=\sqrt[n\left(\sum x y\right)-\left(\sum x \sum y\right)]{\frac{\left[n \sum x^{2}-\left(\sum x\right)^{2} \mid n \sum y^{2}-\left(\sum y\right)^{2}\right]}{[n}}
$$

\section{Keterangan :}

$\mathrm{r}=$ Koefisien korelasi

$\mathrm{x}=$ Skor butir

$\mathrm{y}=$ Skor total butir

$\mathrm{n}=$ jumlah sampel (responden) 
Uji validitas diperoleh dengan cara mengkorelasikan setiap skor item dengan total skor item dalam setiap peubah, hasil korelasi tersebut dibandingkan dengan nilai kritisnya pada taraf signifikan 0,05 atau 5\%, jika hasil koefisien tersebut lebih besar dari nilai kritisnya maka alat ukur tersebut dikatakan valid.

Pada perhitungan uji validitas dengan menggunakan SPSS for windows versi 21 hasil uji validitas dapat dilihat pada nilai $\mathrm{r}$ hitung pada colom corrected item total correlation. Nilai $r$ hitung tersebut disesuaikan dengan nilai $r$ tabel. Jika nilai $r$ hitung diatas nilai $r$ tabel maka item soal tersebut dinyatakan valid. Untuk melihat $r$ tabel disesuaikan dengan jumlah responden yang digunakan untuk uji validitas, kemudian dilihat nilai $\mathrm{r}$ tabel pada kolom $\mathrm{r}$ product moment.

Dalam uji reliabilitas ini dapat diukur dengan metode konsistensi interval dengan tehnik reliabilitas alpha. Kriterianya bila koefisien reliabilitas > dari rtabel maka dapat dikatakan reliable. Dan dapat dihitung dengan rumus :

$$
r i=\frac{(k)}{k-1} \frac{\left[1-\sum a b^{2}\right]}{a t^{2}}
$$

\section{Keterangan :}

ri $\quad=$ Reliabilitas instrument

$\mathrm{k} \quad=$ Banyaknya butir pertanyaan

$\mathrm{ab}^{2} \quad=$ Jumlah variance butir

$\mathrm{at}^{2} \quad=$ Varian total

Pada perhitungan SPSS for windows versi 21 validitas dan instrument dinyatakan reliabel jika memiliki nilai Cronbach's Alpha $>0,60$. Teknik analisa data yang digunakan adalah observasi. Dalam penelitian ini peneliti menggunakan metode analisis data yang bersifat deskriptif - kuantitatif.

\section{HASIL DAN PEMBAHASAN}

Sebelum instrument penelitian dibuat sebagai alat pengumpul data maka peneliti melakukan uji validitas dan reliabilitas sehingga akan didapatkan data penelitian yang sesuai dengan tujuan dan valid. Hasil uji validitas dapat dilihat 
pada table berikut ini :

Tabel 1 Hasil Uji Reliabilitas Instrumen

\begin{tabular}{|c|c|}
\hline Cronbach's Alpha & $\mathrm{N}$ of Items \\
\hline .957 & 10 \\
\hline
\end{tabular}

Tabel diatas menunjukkan bahwa nilai cronbach alfa diatas nilai 0,6 sehingga instrument penelitian ini dapat dinyatakan reliable karena nilai cronbach's alfa $=0,957>0,6$.

Tabel 2 Hasil Uji Validitas Instrumen

\begin{tabular}{|r|r|r|r|r|}
\hline & $\begin{array}{c}\text { Scale Mean if } \\
\text { Item Deleted }\end{array}$ & $\begin{array}{c}\text { Scale Variance if } \\
\text { Item Deleted }\end{array}$ & $\begin{array}{c}\text { Corrected Item- } \\
\text { Total Correlation }\end{array}$ & $\begin{array}{c}\text { Cronbach's Alpha } \\
\text { if Item Deleted }\end{array}$ \\
\hline Soal 1 & 13.60 & 14.317 & .955 & .946 \\
Soal 2 & 13.60 & 14.317 & .955 & .946 \\
Soal 3 & 13.60 & 15.352 & .657 & .958 \\
Soal 4 & 13.80 & 15.062 & .738 & .955 \\
Soal 5 & 13.60 & 14.317 & .955 & .946 \\
Soal 6 & 13.70 & 14.907 & .764 & .954 \\
Soal 7 & 13.70 & 15.114 & .706 & .956 \\
Soal 8 & 13.70 & 14.907 & .764 & .954 \\
Soal 9 & 13.80 & 15.062 & .738 & .955 \\
Soal 10 & 13.70 & 14.493 & .882 & .949 \\
\hline
\end{tabular}

Tabel di atas menunjukkan bahwa untuk mengetahui hasil uji validitas maka yang dilihat adalah nilai $\mathrm{r}$ hitung pada kolom corrected item total correlation. Nilai $\mathrm{r}$ hitung dilihat pada kolom corrected item total correlation harus diatas nilai $r$ tabel. Nilai $r$ tabel pada penelitian ini $=0,444(n=20)$, nilai $r$ hitung pada kolom corrected item total correlation diperoleh dari perhitungan program SPSS dimana nilai yang diperoleh kuesioner yang telah diisi oleh responden dimasukkan dalam tabulasi data kemudian dilakukan perhitungan dengan program SPSS dan diperoleh nilai $r$ hitung. Hasil uji validitas dalam penelitian ini menunjukkan bahwa nilai $r$ hitung semua soal diatas nilai $r$ tabel yaitu untuk soal nomer 1, 2 dan dan nomer 5 nilai 0,995, soal nomer 3 diperoleh 
nilai 0,657 , soal nomer 4 dan 9 diperoleh nilai 0,738 , soal nomer 6 dan 8 diperoleh nilai 0,764 , soal nomer 7 dipeorleh nilai 0 , 706 dan soal nomer 10 dipeorleh nilai 0,882 . Hasil tersebut menunjukkan bahwa seluruh nilai $r$ hitung pada butir soal instrument penelitian diatas nilai $r$ tabel sehingga instrument penelitian dinyatakan valid.

Uji normalitas adalah untuk melihat apakah nilai residual terdistribusi normal atau tidak.Jadi, uji normalitas bukan dilakukan pada masing-masing variabel tetapi pada nilai residualnya. Hasil uji normalitas melalui normal probability plot diperoleh hasil sebagai berikut:

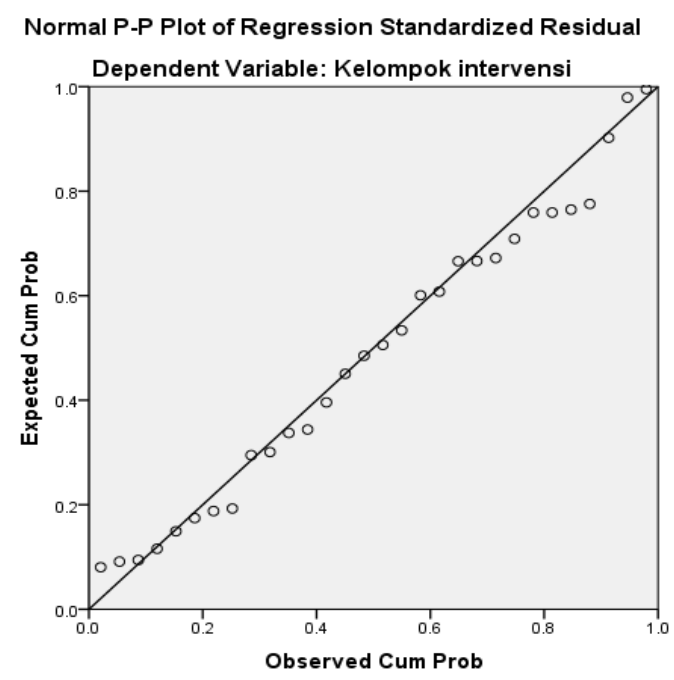

Gambar 1 Grafik Normalitas Data

Dari hasil pengujian pretest yang dilakukan dengan hasil sebagai berikut:

Tabel 3 Distribusi Frekuensi Skor Baku Pretest

\begin{tabular}{|c|c|c|c|c|c|c|}
\hline No & Nilai & $\mathbf{X}_{\mathbf{i}}$ & $\mathbf{f}_{\mathbf{i}}$ & $\mathbf{f}_{\mathbf{i}} \mathbf{X i}$ & $\mathbf{x}_{\mathbf{i}}^{2}$ & $\mathbf{f}_{i} \mathbf{x}_{i}^{2}$ \\
\hline 1 & $40-45$ & 37.5 & 4 & 150 & 1406.25 & 5625 \\
\hline 2 & $46-50$ & 43.5 & 5 & 217,5 & 1892.25 & 9461.25 \\
\hline 3 & $51-55$ & 49.5 & 6 & 297 & 2450.25 & 14701.5 \\
\hline 4 & $56-60$ & 55.5 & 5 & 277.5 & 3080.25 & 15401.25 \\
\hline 5 & $61-65$ & 61.5 & 6 & 369 & 3782.25 & 22693.5 \\
\hline 6 & $66-70$ & 67.5 & 4 & 270 & 4556.25 & 18225 \\
\hline & jumlah & & 30 & 1581 & 17167.5 & 86107.5 \\
\hline
\end{tabular}


Dari hasil pengujian posttest yang dilakukan dengan hasil sebagai berikut:

Tabel 4 Distribusi Frekuensi Skor Baku Postest

\begin{tabular}{|c|c|c|c|c|c|c|}
\hline No & Data & $\mathbf{x}_{\mathbf{i}}$ & $\mathbf{f}_{\mathbf{i}}$ & $\mathbf{f}_{\mathbf{i}} \mathbf{x i}$ & $\mathbf{x}_{\mathbf{i}}^{2}$ & $\mathrm{f}_{\mathrm{i}} \mathbf{x}_{i}^{2}$ \\
\hline 1 & $60-65$ & 42.5 & 6 & 255 & 1806.25 & 10837.5 \\
\hline 2 & $66-71$ & 68.5 & 7 & 479.5 & 4692.25 & 32845.75 \\
\hline 3 & $72-77$ & 74.5 & 7 & 521.5 & 5550.25 & 38851.75 \\
\hline 4 & $78-83$ & 80.5 & 7 & 563.5 & 6480.25 & 45361.75 \\
\hline 5 & $84-90$ & 87 & 3 & 261 & 7569 & 22707 \\
\hline & jumlah & 353 & 30 & 2080.5 & 26098 & 150603.75 \\
\hline
\end{tabular}

Nilai Variansi sebagai berikut:

Tabel 5 Nilai Variansi

\begin{tabular}{|c|c|c|}
\hline & Pretest & Posttest \\
\hline $\mathrm{S}^{2}$ & 9.8 & 14.7 \\
\hline $\mathrm{N}$ & 30 & 30 \\
\hline
\end{tabular}

$$
\begin{aligned}
\mathrm{F}_{\text {hitung }} & =\frac{\text { variansi terbesar }}{\text { variansi terkecil }} \\
& =\frac{14.7}{9.8} \\
& =1.5
\end{aligned}
$$

Dari pengujian data diatas maka dapat diketahui bahwa kelas eksperimen dan kelas kontrol mempunyai variansi yang sama (homogen).

Hasil uji normalitas Kolmogorov-Smirnov pada tabel 1 didapatkan data semua hasil signiikasnsi baik hasil belajar pretest maupun hasil belajar posttest lebih dari 0,05 (0,213 untuk pre test dan 0,051 untuk post test)), maka dapat disimpulkan bahwa data berdistribusi normal. Hasil uji one sampel $\mathrm{T}$ test menunjukkan bahwa nilai $\rho=0,00$ dari hasil pres dan post test berarti nilai $\rho<\alpha$, dengan $\alpha=0,05$ maka hal ini menunjukkan terdapat perbedaan hasil belajar siswa dalam mengerjakan soal IPA sebelum dan setelah dilakukan metode talking stick. Berdasarkan nilai rata-rata kelompok menunjukkan data nilai rata-rata pada saat pretest sebesar 56, 8, dan nilai rata-rata kelompok post test sebesar 71 .

Pembelajaran cooperative dikenal dengan pembelajaran secara berkelompok yang sistem pengajarannya memberi kesempatan kepada anak didik untuk bekerja sama dengan sesama siswa dalam tugas-tugas yang terstruktur. Pembelajaran kooperatif mengandung pengertian sebagai suatu sikap 
atau perilaku bersama dalam bekerja atau membantu diantara sesama dalam struktur kerja sama yang teratur dalam kelompok, yang terdiri dari dua orang atau lebih, dimana keberhasilan kerja sangat dipengaruhi oleh keterlibatan dari setiap anggota kelompok itu sendiri.

Model pembelajaran cooperative dikembangkan untuk mencapai hasil belajar berupa prestasi akademik, toleransi, menerima keragaman, dan pengembangan keterampilan sosial. Lebih lanjut tujuan pokok pembelajaran kooperatif adalah untuk dapat memaksimalkan belajar siswa agar peningkatan prestasi akademik dan pemahaman tercapai dengan, baik secara individu maupun secara kelompok.

Salah satu contoh model pembelajaran yang bias diterapkan di kelas 4 SD yaitu model pembelajaran talking stick. Model pembelajaran talking stick merupakan satu dari sekian banyak model pembelajaran kooperatif. Model pembelajaran ini dilakukan dengan bantuan tongkat. Tongkat dijadikan sebagai jatah atau giliran untuk berpendapat atau menjawab pertanyaan dari guru setelah siswa mempelajari materi pelajaran. Talking stick merupakan model pembelajaran kelompok dengan bantuan tongkat. Kelompok yang memegang tongkat terlebih dahulu wajib menjawab pertanyaan dari guru setelah mereka mempelajari materi pokok.

Hasil peneliti ini menunjukkan bahwa proses belajar siswa kelas 4 sekolah dasar masih menggunakan metode pembelajaran konvensional yang terpusat pada guru sehingga hasil belajar siswa masih belum mencapai target secara optimal. Guru mempunyai peranan penting dalam menentukan keberhasilan murid dalam belajar. Dalam meningkatkan hasil belajar murid khususnya hasil belajar pada mata pelajaran IPA sangat dibutuhkan kemampuan dari guru untuk mengembangkan kreasi mengajar, mampu menarik minat murid untuk belajar IPA. Dengan demikian guru tidak hanya mentransfer ilmu yang dimilikinya melainkan juga mempertimbangkan aspek intelegensi dan kesiapan belajar murid, sehingga murid tidak mengalami depresi mental seperti kebosanan, mengantuk, frustasi bahkan anti pati terhadap mata pelajaran IPA. sifat guru yang terkesan 
mendominasi saat pemberian materi pelajaran, tanpa diselingi tindakan yang bisa membuat murid lebih rileks dan senang mengikuti proses pembelajaran. Dengan munculnya rasa bosan dalam diri murid.

Proses pembelajaran yang dilakukan dengan metode konvensional atau lebih terpusat pada guru akan kurrang memberikan semangat dan menumbuhkan kreatitifas siswa, sehingga guru harus dapat menggunakan metode pembelajaran yang lebih inovatif dan reatif agar dapat mendongkrak hasil belajar siswanya. Selain menggunakan model yang lebih variatif dan inovatif guru juga perlu mengembangkan berbagai sumber belajar yang dapat menunjang kegiatan pembelajaran, sehingga kegiatan pembelajaran berlangsung dengan lebih menarik dan dapat mengembangkan keaktifan serta kreatifitas siswa yaitu dengan menggunakan aneka sumber belajar. Dengan menerapkan model pembelajaran kooperatif Talking Stick maka kegiatan pembelajaran dapat berlangsung dengan lebih menarik dan menyenangkan sehingga siswa lebih aktif dan dapat mengembangkan pengetahuan yang dimiliki dengan mencari berbagai sumber belajar sendiri.

Hasil belajar pre test mengindikasikan masih banyak nili hasil belajar siswa yang kurang memuaskan sehingga dibutuhkan metode pembelajaran yangn lebih inovatif dan kreatif untuk itulah digunakan model pembelajaran talking stick agar dapat meningkatkan hasil belajar siswa. Hasil belajar post tes siswa mengindikasikan nilai siswa yang cukup memuaskan sehingga hasil penelitian ini dapat menunjukkan bahwa metode pembelajaran talking stik dapat mempengaruhi peningkatan hasil belajar siswa pada mata pelajaran IPA pada siswa kelas 4 sekolah dasar.

\section{SIMPULAN}

Simpulannya adalah terdapat perbedaan hasil belajar siswa dalam mengerjakan soal materi IPA yang ditunjukkan dengan nilai $t_{\text {hitung }}>t_{\text {tabel }}$ maka $19,03>2,00172$. Dan model pembelajaran kooperatif learning type talking stik dapat mempengaruhi peningkatan hasil belajar siswa pada mata pelajaran IPA pada 
siswa kelas 4 sekolah dasar. Hasil penelitian ini sebaiknya digunakan untuk meningkatkan pemahaman siswa dalam mengikuti pelajaran IPA kelas 4 SD. Penulis berharap adanya penelitian lebih lanjut pada masalah yang sama dengan ruang lingkup yang lebih luas untuk memperbaiki model pembelajaran yang sudah berjalan melalui dukungan metode yang tepat dalam meningkatkan hasil belajar dan prestasi belajar siswa

\section{DAFTAR PUSTAKA}

Hosnan, M. 2014. Pendekatan Saintifik dan Kontekstual dalam Pembelajaran Abad 21. Bogor: Ghalia Indonesia.

Kurniasih dan Sani. 2015. Model Pembelajaran. Yogyakarta: Kata Pena.

Pradnyani, dkk. 2013. Pengaruh Model Numbered Head Together Terhadap Prestasi Belajar Matematika ditinjau dari Kebiasaan di SD". Jurnal Pendas, Vol 3. 2013.

Setyani, Novia Ika. 2013. Penggunaan Media Sosial Sebagai Sarana Komunikasi Bagi Komunitas. Jurnal Komunikasi Universitas Sebelas Maret, Vol 2. 2013.

Suprijono, Agus. 2015. Cooperative Learning: Teori dan Aplikasi PAIKEM. Yogyakarta : Pustaka Pelajar.

Siregar, Suriani. 2015. Pengaruh Model Pembelajaran Talking Stick Terhadap Hasil Belajar Dan Aktivitas Visual Siswa Pada Konsep Sistem Indra. Jurnal Biotik, Vol. 3, No. 22015.

Tiara, Dira. 2014. Pengaruh Model Pembelajaran Talking Stick Terhadap Afektif Receiving Dan Responding Siswa. Jurnal Unila, Vol 2. 2014. 